\title{
$\angle S$ Research Square \\ The Use of Data Science to Analyse Physiology of Oxygen Delivery in the Extracorporeal Circulation
}

\section{Marceli Lukaszewski ( $\nabla$ marceliluk@gmail.com )}

Uniwersytet Medyczny im Piastow Slaskich we Wroclawiu https://orcid.org/0000-0002-4298-3178

Rafal Lukaszewski

Accenture

\section{Kinga Kosiorowska}

Uniwersytet Medyczny im Piastow Slaskich we Wroclawiu

\section{Marek Jasinski}

Uniwersytet Medyczny im Piastow Slaskich we Wroclawiu

\section{Research article}

Keywords: Extracorporeal circulation, goal-directed perfusion, data science, oxygen delivery, pump flow, haemodynamics

Posted Date: July 25th, 2019

DOI: https://doi.org/10.21203/rs.2.11896/v1

License: (c) (1) This work is licensed under a Creative Commons Attribution 4.0 International License. Read Full License

Version of Record: A version of this preprint was published at BMC Cardiovascular Disorders on December 1st, 2019. See the published version at https://doi.org/10.1186/s12872-019-01301-6. 


\section{Abstract}

Background Recent scientific reports brought into light a new concept of goal-directed perfusion (GDP) that aims to recreate physiological conditions in which the risk of end-organ malperfusion is minimalized. The aim of our study was to analyse patient's interim physiology while on cardiopulmonary bypass based on the haemodynamic and tissue oxygen delivery measurements. We also aimed to create a universal formula that may help in the further implementation of the GDP concept. Methods We retrospectively analysed patients operated at Wroclaw University Hospital between June 2017 and December 2018. Since our observations provided a huge amount of data, including the patient's demographics, surgery details, and the perfusion-related data, the Data Science methodology was applied. Results A total of 272 (mean age $62.5 \pm 12.4,74 \%$ male) cardiac surgery patients were included in the study. To study the relationship between haemodynamic and tissue oxygen parameters, the data for three different values of DO2i $(280 \mathrm{ml} / \mathrm{min} / \mathrm{m} 2,330 \mathrm{ml} / \mathrm{min} / \mathrm{m} 2$ and $380 \mathrm{ml} / \mathrm{min} / \mathrm{m} 2)$, were evaluated. Each set of those lines showed a descending function of $\mathrm{Cl}$ in $\mathrm{Hb}$ concentration for the set D02i. Conclusions Modern calculation tools make it possible to create a common data platform from a very large database. Using that methodology, we created models of haemodynamic compounds describing tissue oxygen delivery. The obtained unique patterns may both allow the adaptation of the flow in relation to the patient's unique morphology that changes in time and contributes to the wider and safer implementation of tailored to individual patient's needs perfusion strategy.

\section{Background}

The emergence of extracorporeal circulation (ECC) has been a milestone in a history of heart surgery. Throughout the years, the ECC procedure of commencing the heart-lung machine and switching off a heart together with a pulmonary circulation from a bloodstream is the gold standard of the majority of cardiac surgery procedures. Nonetheless, the ECC procedure is associated with significant postoperative complications, occurring either de novo or as an exacerbation of existing organ dysfunctions. It may also inflict on the coagulation system and contribute to the initiation of the vasoplegic syndrome [1]. Recently, much attention has been devoted to the detrimental effects of inadequate organ perfusion on cardiopulmonary bypass (CPB) [2]. The current widely accepted CPB management strategies are based on simplified schemes including regulation of core perfusion parameters, thus not restoring patient's unique physiological circulation. The pump flow rate usually remains constant and is set on 2.2-2.4 $\mathrm{I} / \mathrm{min} / \mathrm{m}^{2}[3]$. The perfusion pressure that optimizes transmembrane transport is maintained above 50 $\mathrm{mmHg}$, which is the lowest value of cerebral blood flow autoregulation [4]. The problem of ECC management is aggravated by the lack of EBM-based standards covering the basic haemodynamic parameters, i.e. pump flow rate and perfusion pressure as well as haemodilution range or indications for the vasoconstrictors use. This has led clinicians to adapt different ranges of defined core parameters for guiding the perfusion throughout cardiac surgical units worldwide [1][2][4].

A haemodynamic patient-heart-lung machine model aims to study the disparity between the patient's unique haemodynamic during ECC procedure and CPB settings. The current perfusion protocols that 
based solely on physiological haemodynamic parameters, such as $\mathrm{Cl}$ or perfusion pressure, and subsequently applying the same average parameters for each patient, do not seem adequate, since the initiation of the heart-lung machine changes the physiological haemodynamic conditions. Therefore, the implementation of non-invasive real-time monitoring of oxygen transport and haemodynamics have become an intrinsic factor for the newly introduced concept, a so-called Goal-Directed Perfusion (GDP). The aim of this concept is to restore the physiological conditions of the cell and tissue respiration during ECC by optimizing both tissue oxygen delivery and extraction. The evidence of this concept is very limited with only a handful of articles demonstrating the favourable clinical effects on the reduction of CPBrelated complications such as kidney or CNS injury. The oxygen supply threshold $\left(\mathrm{DO}_{2}\right)$, below which the deterioration of end-organ function has been observed, was set above $272 \mathrm{ml} / \mathrm{m}^{2} / \mathrm{min}$ [5][6]. Additionally, new parameters determining the adequate oxygen transport like percentage oxygen saturation of venous blood $\left(\mathrm{SvO}_{2}\right)$, oxygen consumption $\left(\mathrm{VO}_{2}\right)$, ratio of oxygen consumed to oxygen delivered $\left(\mathrm{O}_{2} \mathrm{ER}\right)$, and oxygen delivery indexed to body surface area to carbon dioxide production indexed to body surface area ratio $\left(\mathrm{DO}_{2} \mathrm{i} / \mathrm{VCO}_{2} \mathrm{i}\right)$ were adopted. Yet the $\mathrm{DO}_{2} \mathrm{i} / \mathrm{VCO}_{2} \mathrm{i}$ ratio often remains blurred due to the frequent $\mathrm{CO}_{2}$ insufflations into the operating field for the anti-embolic purposes.

$\mathrm{DO}_{2}=$ pump flow $\times[(\mathrm{Hg} \times$ Sat $\times 1,36)+(0,003 \times \mathrm{PaO} 2)]$

$\mathrm{DO}_{2}$ is directly proportional to the oxygen content in the blood and the pump flow rate therefore enables the adjustment of these two parameters to obtain the satisfactory $\mathrm{DO}_{2}$ value. Perfusion pressure depends on the cardiac output and the vascular tone, whereas while on CPB it depends mainly on the flow rate and blood viscosity. Systemic vascular resistance, as usually practiced, can be modified through vasoactive agents [7].

The aim of our observational study was to find physiological relationships between the patient's haemodynamics and the heart-lung machine settings that would then allow for the further widespread introduction of the perfusion tailored to the individual patient's need concept throughout units around the world.

\section{Methods}

We performed a retrospective analysis of 272 consecutive cardiac surgery patients operated at Wroclaw University Hospital between June 2017 and December 2018. Each procedure was performed with the use of the S5 Heart-Lung Machine (LivaNova PLC, London, UK) equipped with the System M real-time noninvasive monitoring (Spectrum Medical, Gloucester, UK).. All the procedures were performed according to the ward standards in normothermia. The patients' agreement for treatment and data collection was approved by the local Bioethics Committee.

Data collection and statistical analysis 
The dataset of 272 cases which counts up to over 351 thousand rows of data was collected from both electronic medical records and the VIPER data management system where all the perfusion-related data were collected. Demographic data were expressed as mean values with either a standard deviation (SD) for continuous variable data or as a percentage of the total for categorical data (Table 1). We compared altogether: patient baseline characteristics with operative details obtained from electronic medical records, results of sensors in-line monitoring and pump flow rate measurements. The enormous amount of data and the diversity of the data pattern determined to use the Data Science calculation tools [8]. In Data Science nomenclature, our estimates are described as: structured data (e.g., laboratory results), semi-structured data (e.g., sensor data), and unstructured data (e.g., patient notes) [9][10][11]. Additionally, using the Data Science capabilities we looked for adequate pump flow rates for which the relevant GDP conditions such as $\mathrm{DO}_{2}>280 \mathrm{ml} / \mathrm{m}^{2} / \mathrm{min}, \mathrm{SvO}_{2}>68 \%$ and $\mathrm{MAP}>60 \mathrm{mmHg}$ were met. Our toolset was based in on Anaconda Distribution (Anaconda Inc., https://www.anaconda.com), Python 3.6 (Python Software Foundation, https://www.python.org), and Jupyter Notebook (Jupyter Project, https://jupyter.org). Data cleaning and analysis was done using Pandas (Python Data Analysis Library), whereas visualization was done with Matplotlib (Matplotlib Development Team, https://matplotlib.org) and Seaborn libraries (https://seaborn.pydata.org). All those applications use Berkeley Software Distribution (BSD) type of license, meaning that they are free for distribution, modification, and private and commercial use while not requiring any liabilities in return. All the data, both structured and unstructured were firstly gathered in a Microsoft Excel (Microsoft office package, https://products.office.com/pl-pl/excel) format with each patient bookmarked with a separate spreadsheet. From there it was imported into a Jupyter Notebook, where, using Python Pandas module, it was merged into one big dataset that used the time for its main index. It was then scrapped from duplications and empty rows, cleaned from unnecessary information and the missing information was interpolated from the nearby points. Those operations were necessary to create a data platform that was then investigated by adding to it different set of constrains. Finally, visual analysis has been done with the use of $2 \mathrm{D}$ and $3 \mathrm{D}$ plots.

\section{Results}

A total of 272 (mean age $62.5 \pm 12.4,74 \%$ male) cardiac surgery patients were included in this study. Nearly half of them (49.5\%) underwent isolated CABG procedure, whereas $34.4 \%$ underwent other single procedure. A double procedure was conducted on $15.6 \%$ of patients. One patient underwent a triple procedure. Demographic findings of the study population are presented in Table 1 . The formation of heterogeneous information derived from patient baseline characteristics along with operative details, and results of in-line real-time CPB monitoring and pump flow rate measurements, created a common platform for coherent multi-modal data processing. As the methodology of Data Science enables the analysis of various types of data, rejection of erroneous readings, and the use of regression methods we aimed to identify and analyse diagnostic and therapeutic features for ECC. It was ensured that the database has been cleared from any duplications and empty rows. The first visual analysis of the gathered data shows haemoglobin concentration and cardiac index $(\mathrm{Cl})$ value on correspondingly $\mathrm{x}$ and 
$y$-axis (Fig.1). Oxygen delivery $\left(\mathrm{DO}_{2} \mathrm{i}\right)$ has been illustrated with colour, where the darker shades correspond with lower values. The image reveals a predictable pattern, that the $\mathrm{DO}_{2} \mathrm{i}$ level goes up with both $\mathrm{Hb}$ and $\mathrm{Cl}$. It also reveals that most of the measurements were taken for $\mathrm{Cl}$ set between $1,3-2,8 \mathrm{~L} / \mathrm{min} / \mathrm{m}^{2}$ and $\mathrm{Hb}$ values between $9-12 \mathrm{~g} / \mathrm{dL}$. What striking is that the database is overfilled with $\mathrm{DO}_{2} \mathrm{i}$ values staggeringly lower than $280 \mathrm{~mL} / \mathrm{min} / \mathrm{m}^{2}$ which is assumed in our case to be a moderate norm. Continuing data analysis, we carefully selected data for which minimum values of $\mathrm{DO}_{2} \mathrm{i}$ was at least 280 $\mathrm{mL} / \mathrm{min} / \mathrm{m}^{2}$ and $\mathrm{SvO}_{2}$ was above $68 \%$. Additionally, the impact of outliers points that at random go out of the pattern due to various measurement uncertainties, have been reduced by shortening the database by those rows where $\mathrm{Cl}$ values had less than one hundred corresponding $\mathrm{Hb}$ measurements. Those new constraints left a strong visible pattern in the data (Fig. 2). The arch-shaped cut on the lower part of the scattered data in Figure 2 corresponds to the relationship between $\mathrm{Cl}$ and $\mathrm{Hb}$ for our limit $\mathrm{DO}_{2}$ value. To study the relation, we have extracted the data for three different values $\left(280 \mathrm{ml} / \mathrm{min} / \mathrm{m}^{2}, 330\right.$ $\mathrm{ml} / \mathrm{min} / \mathrm{m}^{2}$ and $380 \mathrm{ml} / \mathrm{min} / \mathrm{m}^{2}$ ) of oxygen delivery $\left(\mathrm{DO}_{2} \mathrm{i}\right)$, which were therefore described with weighted linear regression of second order (Fig. 3). Each set of those lines shows a descending function of $\mathrm{Cl}$ in $\mathrm{Hb}$ concentration for the set $\mathrm{DO}_{2} \mathrm{i}$.

\section{Discussion}

Recently, there is accumulating evidence to suggest the trends in current perfusion practice needs to be improved as we experience tremendous technological improvement every day. The discussed new GDP concept ideally creates tailored to the individual patient's needs treatment, and therefore aim to diminish the risk of complications throughout the entire surgical procedure. Consequently, the emerging concept jeopardizes the current widely accepted CPB strategies of organ perfusion based on a constant pump flow rate and the ubiquitous indicators of tissue perfusion such as lactate concentration and urine output, with lactates representing effective tissue perfusion and metabolism balance, and urine output being a vital indicator of renal perfusion. The main goal of GDP is to optimize tissue oxygen delivery and extraction. Noteworthy, the adequate perfusion represented by the flow rate is a crucial component of $\mathrm{DO}_{2}$.

In the current clinical practice, the haemodynamic values used by perfusionists are based solely on observational studies designed on the physiology of a healthy individual. For instance, the pump flow rate is the equivalent of the average calculated cardiac index $(\mathrm{Cl})$. However, the question is being raised whether the haemodynamic parameters observed in a healthy individual can be adapted during ECC when the heart and pulmonary circulation are switched off from the bloodstream and the tangible pump flow rate reflects the unique physiology of cardiac output only to the small extent. Advancement in System $\mathrm{M}$ in-line noninvasive monitoring allows not only for real-time observation of flow rates, both venous and arterial saturation, haemoglobin level, the extent of carbon dioxide production, but also derives calculations of all exponents of oxygen transport. The aim of our study was to find the relationships between the set pump flow rates and the ultimate GDP conditions such as $\mathrm{DO}_{2}>$ 
$280 \mathrm{~mL} / \mathrm{min} / \mathrm{m} 2, \mathrm{SvO}_{2}>68 \%$ and the minimum MAP of $60 \mathrm{mmHg}$. Statistical analysis was performed using Data Science that is a calculation tool being more frequently introduced, for instance, as codes that with good probability can assess if the skin mole will turn into cancer or classify genes responsible for leukaemia [12][13]. In our study, we strived to present how the use of this technology can help in easy visualizing the correlation between factors that would be incalculable elsewhere. Using the described tools, the pattern in the data that corresponds to the relationship between $\mathrm{Cl}$ and $\mathrm{Hb}$ for the same $\mathrm{DO}_{2} \mathrm{i}$ value was derived (Fig. 3). Herein, to ensure a certain level of $\mathrm{DO}_{2}$ at $\mathrm{MAP}>60 \mathrm{mmHg}$, haemoglobin value necessitates the adjustment of the appropriate pump flow rate. The graph illustrates that at $\mathrm{Hg}$ of $10 \mathrm{~g} \%$, the initial pump flow rate within the study population was set on $2.2 \mathrm{l} / \mathrm{min} / \mathrm{m}^{2}$, while at $\mathrm{Hg}$ level of $8 \mathrm{~g} \%$ the pump flow rate should be sustained on approximately $2.61 / \mathrm{min} / \mathrm{m}^{2}$. The described relationship is the part of the GDP concept, however, the perfusion pressure above $60 \mathrm{mmHg}$ is an additional parameter that has been analysed.

\section{Conclusions}

The presented observations reflect the substantial mechanisms in the newly created haemodynamic patient-heart-lung machine model (Fig.4). Nevertheless, the presented concept requires further observation. Appropriate models dedicated to higher perfusion pressures and different $\mathrm{DO}_{2}$ values should be evaluated as it would be extremely useful in managing patients concurrently affected particularly by primary cerebral and visceral hypoperfusion. The revealed relationship outlines the basic values for the initial settings of the heart-lung machine to optimize perfusion during ECC, and in each individual, perfusion strategy should be individualized to the patient's unique physiology that changes over time.

\section{List Of Abbreviations}

CABG - coronary artery bypass grafting

$\mathrm{Cl}$-cardiac index

CPB-cardiopulmonary bypass

$\mathrm{DO}_{2}$-oxygen delivery

EBM-evidence-based medicine

ECC-extracorporeal circulation

$\mathrm{DO}_{2} \mathrm{i}$ - oxygen delivery indexed to Body Surface Area

ec - extracorporeal

GDP-goal-directed perfusion 
$\mathrm{Hb}$-haemoglobin

MAP-mean arterial pressure

$\mathrm{O}_{2}$ ER-ratio of oxygen consumed to oxygen delivered

$\mathrm{SVO}_{2}-$ mixed venous oxygen saturation

$\mathrm{VCO}_{2}-$ carbon dioxide production

$\mathrm{VO}_{2}$-oxygen consumption

\section{Declarations}

Ethics approval and consent to participate: Not applicable.

Consent for publication: Written informed consent was obtained from the patient for the publication of this case report and any accompanying images. A copy of the consent form is available for review from the corresponding author.

Availability of data and material: All available information is contained within the present manuscript.

Competing interests: The authors declare that they have no competing interests.

Funding: There was no funding received for this manuscript.

Authors' contributions: ML: Concept/design, Data analysis/interpretation, Data collection. RL:

Concept/design, Data analysis/interpretation, Drafting article. KK: Concept/design, Data collection, Drafting article. MJ: Critical revision of article, Approval of article. All authors read and approved the final manuscript.

Acknowledgements: None.

\section{References}

[1] Murphy GS, Hessel EA, Groom RC. Optimal Perfusion During Cardiopulmonary Bypass: An EvidenceBased Approach. Anesth. Analg. 2009;108(5):1394-1417.

[2] Shaefi S, Mittel A, Klick J, Evans A, Ivascu NS, Gutsche J, Augoustides JGT. Vasoplegia After Cardiovascular Procedures-Pathophysiology and Targeted Therapy. J. Cardiothorac. Vasc. Anesth. 2018;32(2):1013-1022.

[3] Clowes GHA, Neville WE, Sabga G, Shiboh Y. The relationship of oxygen consumption, perfusion rate, and temperatue to acidosis associated with cardiopulmonary bypass. Surgery. 1958;44:220-223. 
[4] Barry AE, Chaney MA, London MJ. Anesthetic Management during Cardiopulmonary Bypass: A Systematic Review. Anesth. Analg. 2015;120(4):749-769.

[5] Ranucci M, Johnson I, Willcox T, Baker RA, Boer C, Baumann A et al. Goal-directed perfusion to reduce acute kidney injury: A randomized trial. J. Thorac. Cardiovasc. Surg. 2018;156(5):1918-1927.

[6] Awad H, Essandoh M. Goal-Directed Oxygen Delivery During Cardiopulmonary Bypass: Can This Perfusion Strategy Improve Biochemical and Clinical Neurologic Outcomes?. J. Cardiothorac. Vasc. Anesth. 2018;32(6):2493-2494.

[7] Groom RC. Is it Time for Goal-Directed Therapy in Perfusion. J. Extra. Corpor. Technol.2017;49(2):P8P12.

[8] Gill J, Prasad V. Improving observational studies in the era of big data. Lancet 2018;392(10149):716717.

[9] Kong HJ. Managing Unstructured Big Data in Healthcare System. Heal. Inf. Res 2019;25(1):1-2.

[10] Orphanidou C. A review of big data applications of physiological signal data. Biophys.

Rev.2019;11:83.

[11] Chung NC, Ping P, Mirza B, Wang W, Wang J, Choi H. Machine Learning and Integrative Analysis of Biomedical Big Data. Genes 2019;10:87.

[12] Walker BN et al.Dermoscopy diagnosis of cancerous lesions utilizing dual deep learning algorithms via visual and audio (sonification) outputs: Laboratory and prospective observational studies. EBioMedicine 2019; doi: 10.1016/j.ebiom.2019.01.028.

[13] Castillo $D$ et al. Leukemia multiclass assessment and classification from Microarray and RNA-seq technologies integration at gene expression level. PLOS ONE 2019;14(2): e0212127.

\section{Tables}

Table 1. Demographic characteristics of the study group. 


\begin{tabular}{|c|c|}
\hline Number of patients (n) & 276 \\
\hline Age (years), mean $\pm S D$ & $62.5 \pm 12.4$ \\
\hline Gender male, n (\%) & $203(73.6)$ \\
\hline Body surface area $(\mathrm{m} 2)$, mean $\pm S D$ & $1.95 \pm 0.21$ \\
\hline Body mass index, mean $\pm S D$ & $28.38 \pm 4.78$ \\
\hline \multicolumn{2}{|l|}{ Risk factors, n (\%) } \\
\hline Coronary artery disease & $190(68.8)$ \\
\hline Hypertension & $188(68.1)$ \\
\hline Diabetes mellitus & $79(28.6)$ \\
\hline Hypercholesterolemia & $59(21.4)$ \\
\hline COPD & $12(4.3)$ \\
\hline ESRD & $3(1.1)$ \\
\hline \multicolumn{2}{|l|}{ Type of surgery, n (\%) } \\
\hline CABG & $137(49.6)$ \\
\hline Other single procedure & $95(34.4)$ \\
\hline Double procedure & $43(15.6)$ \\
\hline Triple procedure & $1(0.4)$ \\
\hline
\end{tabular}

CABG - Coronary bypass grafting; COPD - Chronic obstructive pulmonary disease; ESRD - End stage renal disease;

Figures 


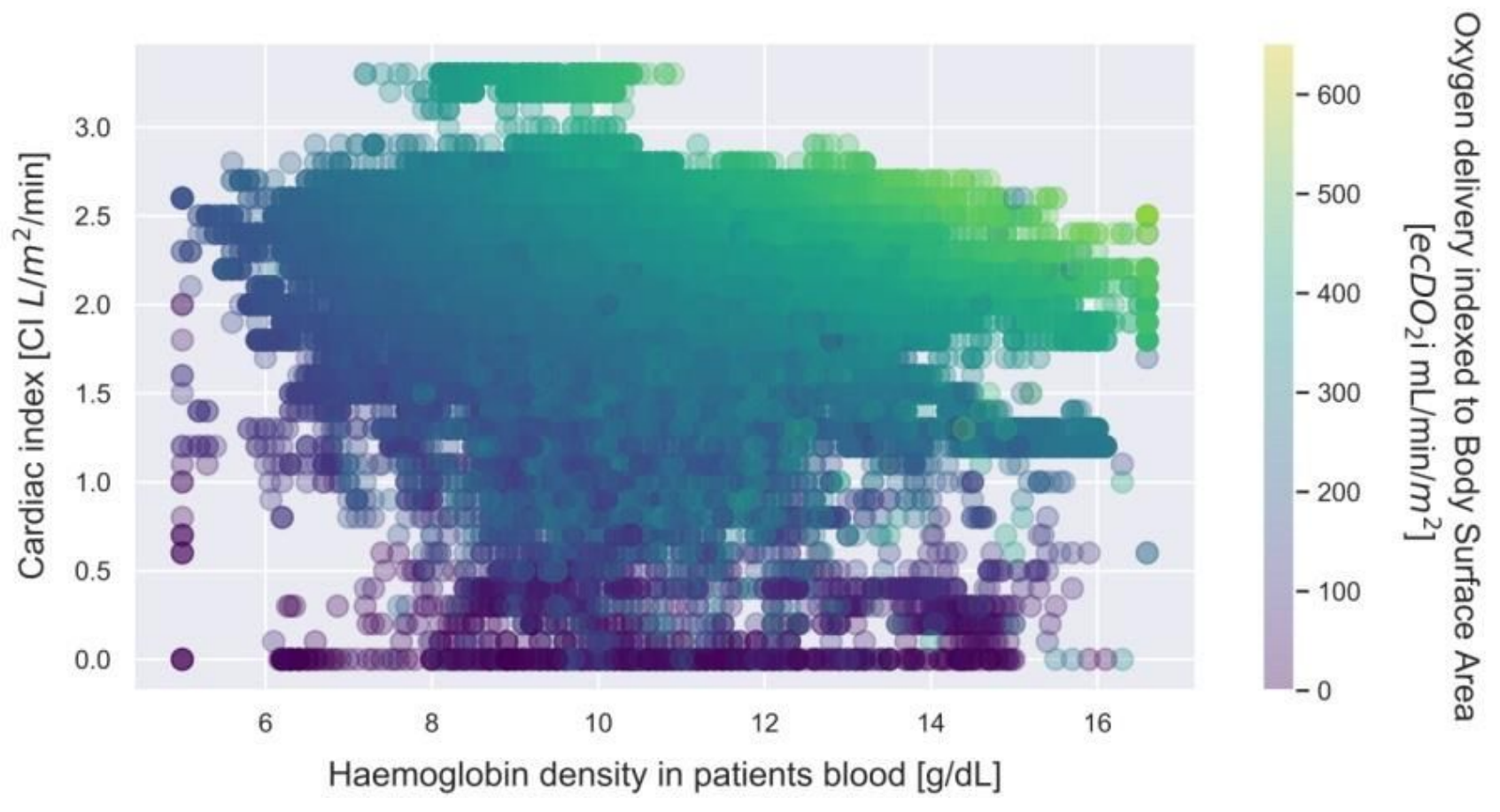

\section{Figure 1}

A full set of the cardiac index data during extracorporeal circulation (ECC), in the function of haemoglobin density and tissue oxygen delivery for patients with mixed venous oxygen saturation (SvO2) above 68\% and mean arterial pressure (MAP) above $60 \mathrm{mmHg}$. Oxygen delivery (DO2i) has been illustrated with colour, where the darker shades correspond with lower values.

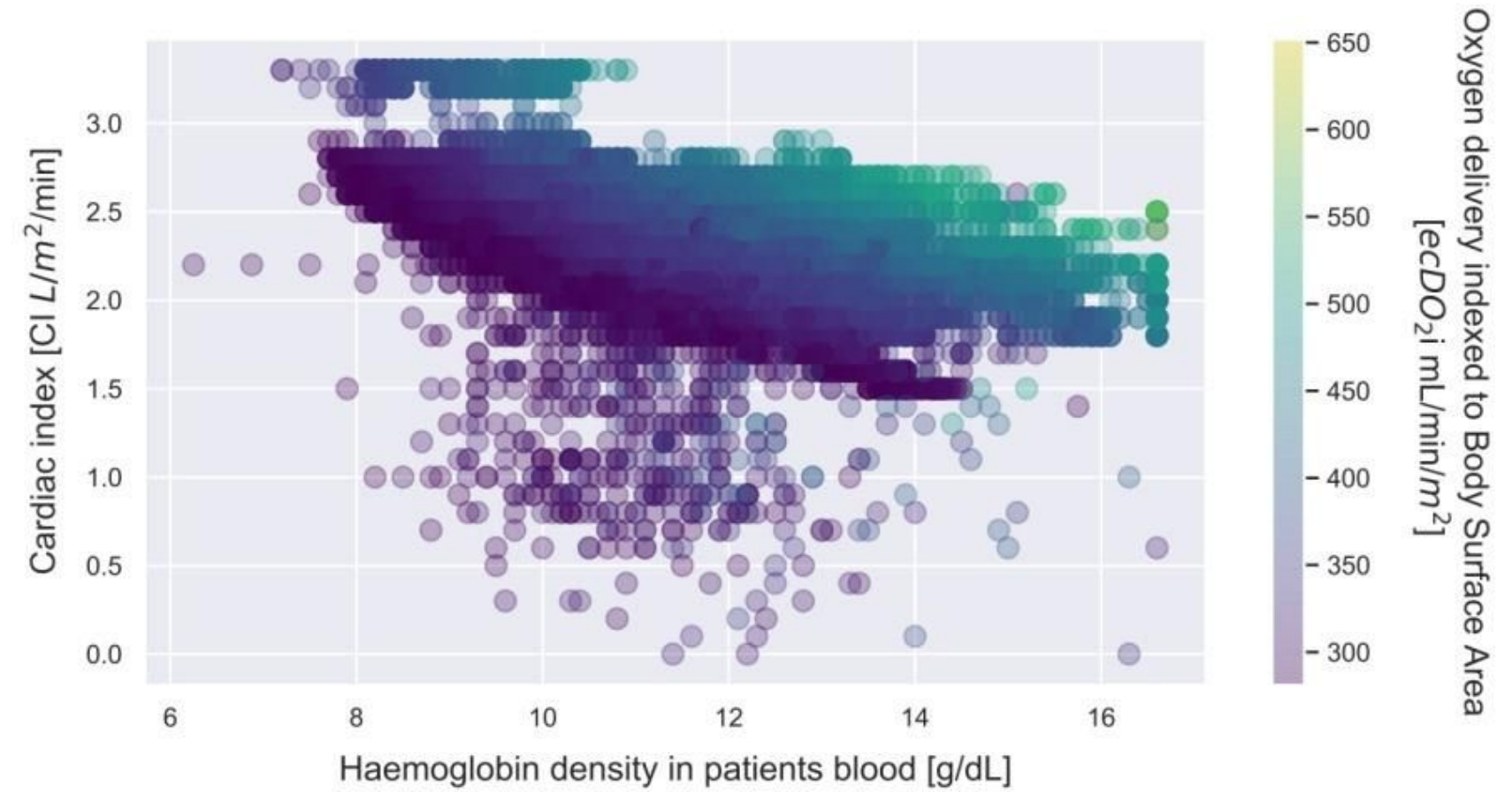

Figure 2 
A set of the cardiac index data during extracorporeal circulation (ECC) for patients with mixed venous oxygen saturation (SvO2) above $68 \%$, mean arterial pressure (MAP) above $60 \mathrm{mmHg}$ and tissue oxygen delivery (DO2) greater than $280 \mathrm{~mL} / \mathrm{min} / \mathrm{m} 2$, in the function of haemoglobin density and tissue oxygen delivery.

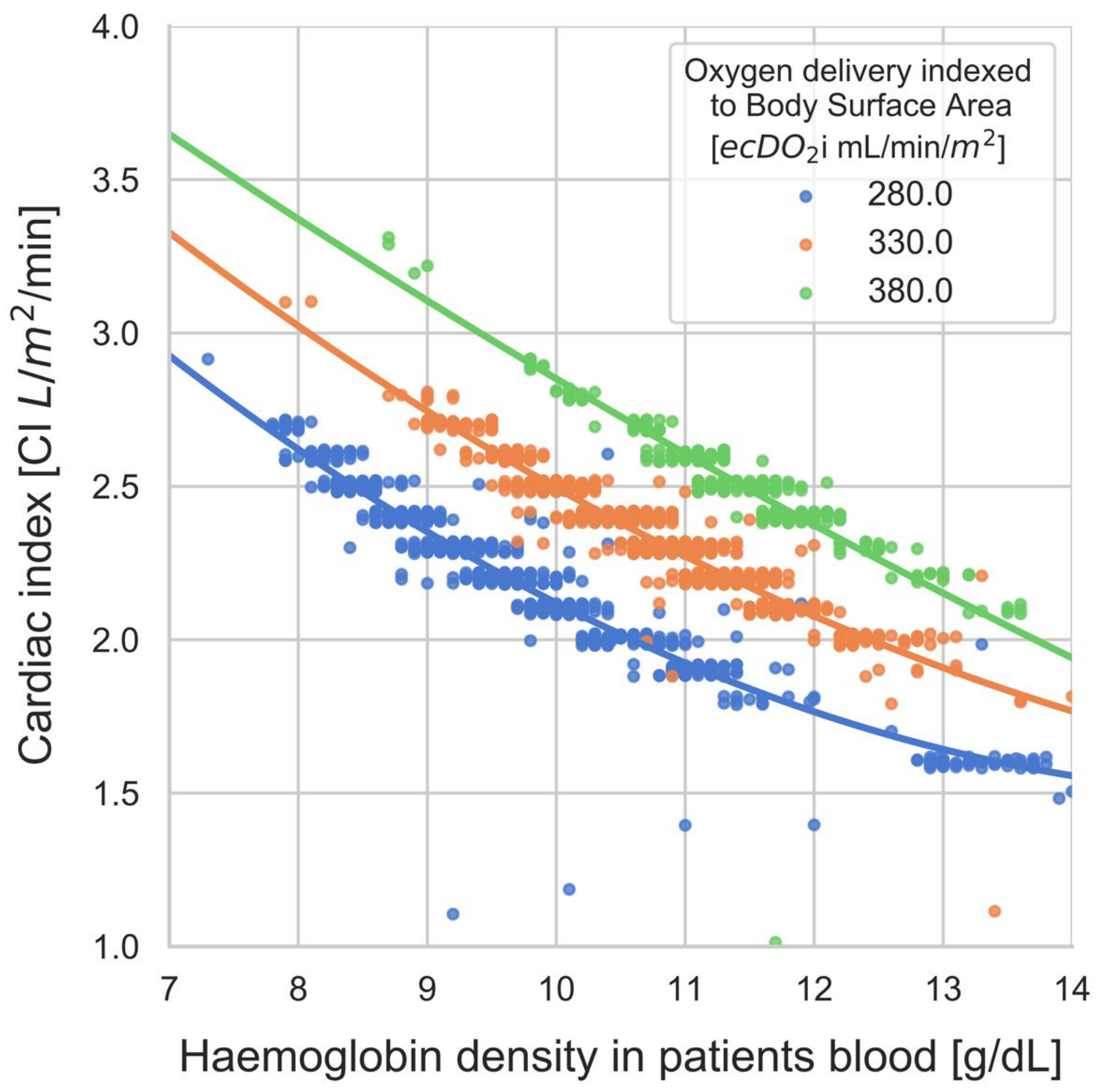

Figure 3

The linear regression curves for three selected oxygen delivery (D02) levels showing the relationship between cardiac index $(\mathrm{Cl})$ and haemoglobin density. 


\section{Data Analysis}

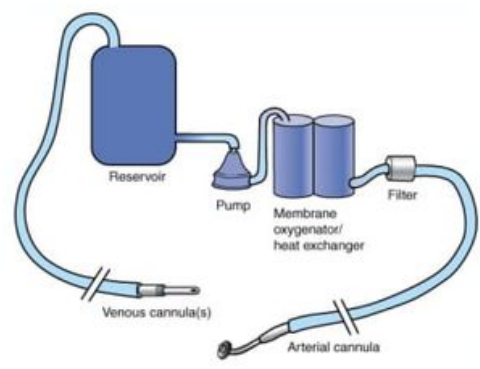

Heart-Lung Machine

Noninvasive in-line real-time monitoring Goal-Directed Perfusion (GDP)

Pump flow rate
Haemodynamic Patient - Heart-Lung Machine Model

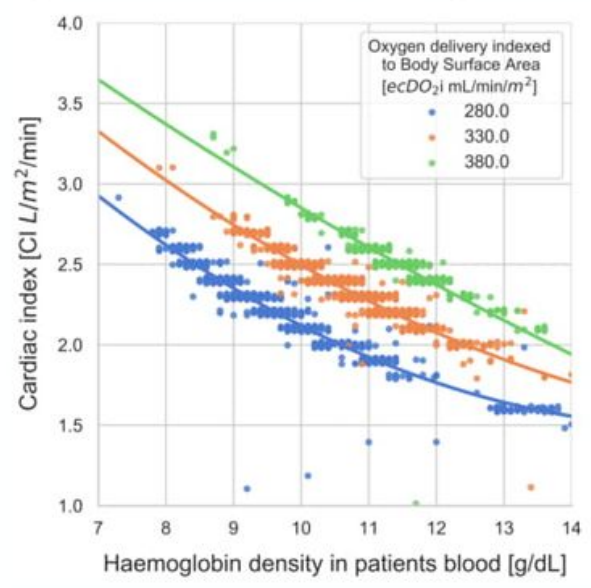

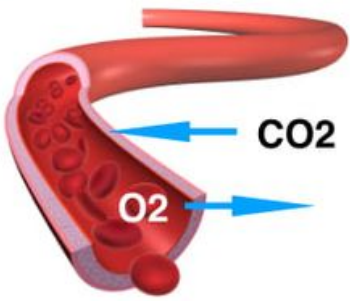

Patient

Tissue oxygen delivery (DO2)

Cardiac Index (Cl)

Haemoglobin level

\section{Figure 4}

A graphical illustration of the haemodynamic patient - heart-lung machine model demonstrating the patient's unique haemodynamics while extracorporeal circulation. 